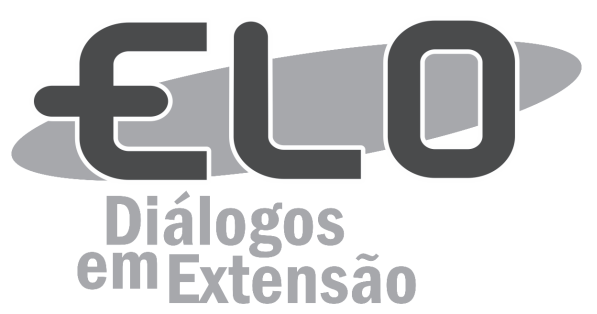

\title{
Discussão sobre a Atuação das ITCPs na Região Sul do Brasil
}

Louise de Lira Roedel Botelho ${ }^{1}$, Fernanda Elis dos Santos ${ }^{2}$, Sandra Vidal Nogueira ${ }^{3}$, Edemar Rotta

Resumo: O presente trabalho teve como objetivo identificar algumas das Incubadoras Tecnológicas de Cooperativas Populares (ITCPs) na região sul do Brasil, fazendo uma rápida análise das suas atuações regionais. A metodologia adotada foi a pesquisa quantitativa e seguiu a sugestão de Merriam (1998) para amostragem em pesquisas quantitativas. Os dados foram extraídos do Mapeamento das Incubadoras Tecnológicas de Cooperativas Populares da Região Sul do Brasil, realizado ao longo dos anos de 2014 e 2015 pela Incubadora Tecnossocial de Cooperativas e Empreendimentos Econômicos Solidários (ITCEES), da Universidade Federal da Fronteira Sul (UFFS). Foram aplicados questionários fechados aos coordenadores das ITCPs, além da coleta de dados secundários extraídos de documentos, publicações, sítios na internet, entre outros. Espera-se que esse panorama apresente a real atuação das ITCPs ou, pelo menos, aproxime-se de suas atividades e desafios enfrentados.

Palavras-chave: Revisão Integrativa. Desafios Enfrentados. Empreendimentos Incubados.

Área Temática: Trabalho e teorias e metodologias em extensão.

\section{Discussion on the Practice of ITCPs in Southern Brazil}

Abstract: This study aimed to identify some of the Technological Incubators of Popular Cooperatives (ITCPS) in southern Brazil, making a quick analysis of their regional performances. The methodology used was quantitative research and followed the suggestion Merriam (1998) for sampling in quantitative research. Data were extracted from the mapping of technological Incubators of Popular Cooperatives of Southern Brazil, conducted over the years 2014 and 2015 by the Incubator Tecnossocial Cooperatives and Solidarity Economic Enterprises (ITCEES), the Federal University of South Border (UFFS). Closed questionnaires were given to coordinators ITCPs, as well as collecting secondary data extracted from documents, publications, websites, among others. It is expected that this situation presents a real performance of ITCPs or at least get close to their activities and challenges faced.

Keywords: Integrative Review. Facing challenges. Incubated Projects.

\section{La discusión sobre la práctica de ITCP en el Sur de Brasil}

Resumen: Este trabajo fue el objetivo identificar algunas de las Incubadoras Tecnológicas de Cooperativas Populares (ITCPs) en el Sur de Brasil, haciendo un rápido análisis de sus actuaciones regionales. La metodología utilizada fue la investigación cuantitativa y siguió la sugerencia de Merriam (1998) para el muestreo en la investigación cuantitativa. Los datos fueron extraídos de lo Mapeamento de Incubadoras Tecnológicas de

\footnotetext{
${ }^{1}$ Doutora. Professora Adjunta II e pesquisadora da Universidade Federal da Fronteira Sul (UFFS), Campus Cerro Largo/ RS. Bolsista de Extensão no País CNPq Nível B. Endereço: Rua Major Antônio Cardoso, 590 - Centro - Prédio do antigo Seminário São José - CEP 97900-000 - Cerro Largo/ RS. Telefone: (55) 3359-3960. E-mail: louisebotelho@uffs.edu.br.

${ }^{2}$ Bacharela em Engenharia Ambiental pela Universidade Federal da Fronteira Sul (UFFS), Campus Cerro Largo. Bolsista EXP-C do CNPq. Endereço: Rua Major Antônio Cardoso, 590 - Centro - Prédio do antigo Seminário São José - CEP 97900-000 - Cerro Largo/ RS. Telefone: (55) 3359-3960. E-mail: ferelis90@hotmail.com.

${ }^{3}$ Doutora. Professora Adjunta I da Universidade Federal da Fronteira Sul (UFFS), Campus Cerro Largo/ RS. Endereço: Rua Major Antônio Cardoso, 590 - Centro -

Prédio do antigo Seminário São José - CEP 97900-000 - Cerro Largo/ RS. Telefone: (55) 3359-3960. E-mail: sandra.nogueira@uffs.edu.br.

${ }^{4}$ Doutor. Professor do Quadro permanente do Programa de Mestrado em Desenvolvimento e Políticas Públicas da Universidade Federal da Fronteira Sul (UFFS), Campus Cerro Largo/RS. Endereço: Rua Major Antônio Cardoso, 590 - Centro - Prédio do antigo Seminário São José - CEP $97900-000$ - Cerro Largo/ RS. Telefone: (55) 3359-3960. E-mail: erotta@uffs.edu.br.
} 
Cooperativas Populares del sur de Brasil, retenida durante los años 2014 y 2015 por las Cooperativas Incubadora Tecnossocial y Empresas de Economia Solidária (ITCEES), de la Universidade Federal de Fronteira Sul (UFFS). Fueron aplicados cuestionarios a los coordinadores de las ITCP, más allá de la collección de datos secundarios extraídos de documentos, publicaciones, sitios de web, entre otros. Se espera que esta situación presenta un rendimiento real de ITCP o, al menos, acerca de sus actividades y desafíos que enfrentan.

Palabras clave: Revisión integradora. Frente a los desafios. Empresas incubadas.

\title{
Introdução
}

A desigualdade social faz parte da realidade e da própria história do Brasil, assim como da humanidade. Segundo Zouain e Torres (2005), a pobreza adquiriu diferentes significados ao longo dos anos na sociedade brasileira e, entre as décadas de 1950-1960, foi reconhecida como uma questão social, oriunda da falta de oportunidades e do crescimento dos "subempregos", elevando o número de pertencentes à classe de baixa renda. A partir da década de 1970, a pobreza se tornou um problema generalizado, muito pautado pela falta de emprego. Tudo isso leva à necessidade da adoção de estratégias de sobrevivência e à expansão da informalidade na economia.

Assim, com o avanço da globalização a partir da década de 90, o Estado precisou rever sua atuação frente a sua administração. Uma das respostas às mudanças sociais caminhou rumo a temática do desenvolvimento humano. Tudo isso voltado a discussão de questões como a educação. Na verdade, a educação tornou-se agente propulsor para uma transformação social por meio de práticas como o apoio às iniciativas de incubadoras de empreendimentos, oferecendo suporte a uma educação "voltada para a consolidação das ideias e da autonomia dos cidadãos" (ZOUAIN e TORRES, 2005).

As incubadoras sociais são instrumentos para assessorar empreendimentos advindos de projetos sociais. Podem ser consideradas um forte canal entre a universidade e a comunidade, ambas unidas, formulando ideias de empreendimentos sustentáveis a favor da comunidade, aliado ao conhecimento acadêmico, (BEZERRA, SILVA e CARVALHO, 2013).

Segundo Barbieri e Cajazeira (2009) apud Pimentel, Oliveira e Reinaldo (2012):

\begin{abstract}
A contribuição das organizações ao desenvolvimento sustentável está centrada em três dimensões: a econômica, a social e a ambiental. Não há um abandono das demais dimensões da sustentabilidade, mas uma concentração no que é específico à atuação das organizações. Os autores concluem que uma organização sustentável é aquela que orienta suas atividades pelas dimensões da sustentabilidade que lhe são específicas e busca alcançar seus objetivos atendendo, simultaneamente, a equidade social, a prudência ecológica e a eficiência econômica (BARBIERI E CAJAZEIRA, 2009, apud PIMENTEL, OLIVEIRA E REINALDO, 2012).
\end{abstract}

As Incubadoras Tecnológicas de Cooperativas Populares (ITCPs) tiveram inspiração no movimento em prol da cidadania contra a fome e a miséria, no qual professores da Fundação Oswaldo Cruz (Fiocruz), sensibilizados com o contexto social da favela vizinha à instituição, identificaram que o principal fator da situação enfrentada, era o desemprego da referida população. Em vista disso, a Fiocruz, em parceria com a Universidade de Santa Maria/RS, fundou uma cooperativa de trabalho, Cooperativa de Manguinhos, formada pelos moradores da região, que prestavam serviços a própria Fiocruz. A partir dessa ação criou-se, em 1996, a primeira iniciativa de ITCP por intermédio da Coordenação de Programas de Pós-Graduação em Engenharia da Universidade Federal do Rio de Janeiro, cujo objetivo inicial foi estabelecer um contato com comunidades das favelas interessadas na formação de cooperativas de trabalho (SOUZA et al., 2003). Com essa iniciativa e sua repercussão, outros grupos, em outras universidades, buscaram informações e fontes para a construção de projetos similares e algumas universidades também iniciaram a construção de outras ITCPs.

Atualmente no Brasil, as ITCPs se encontram vinculadas a dois grandes grupos de articuladores, a Rede Universitária de Incubadoras Tecnológicas de Cooperativas Populares (Rede de ITCPs) e a Rede Unitrabalho (SOUZA et al., 2003). Essas redes, que apoiam as incubadoras de cooperativas populares e ajudam a desenvolver suas ações, visam possibilitar alternativas de trabalho e renda a indivíduos excluídos no mercado de trabalho. 
Neste estudo, financiado pelo $\mathrm{CNPq}^{5}$ pretendeu-se identificar algumas das ITCPs da Região Sul do Brasil e conhecer suas atuações regionais, com o intuito de descrever as principais dificuldades e desafios que essas enfrentaram para exercerem seus papéis na sociedade. O trabalho está organizado em quatro seções, além desta introdução. A seção 2 apresenta a revisão bibliográfica; a seção 3 apresenta a metodologia quantitativa e a revisão bibliográfica integrativa; a seção 4 discute os resultados obtidos; e a seção 5 apresenta as considerações finais do trabalho.

\section{Revisão Bibliográfica}

Conhecer a definição de incubadora é essencial para determinar as características que a constituem e entender o seu papel na sociedade. Segundo Martins et al. (2005), "o termo incubadora significa um ambiente controlado para amparar a vida". Se pensarmos na sua usual utilização, pode-se dizer que as incubadoras "são aparelhos destinados a manter temperatura constante e apropriada para o desenvolvimento de ovos e cultura de microrganismos ou de outras células vivas", assim como nos hospitais, em que a incubadora é responsável por fornecer a um recém-nascido prematuro, um ambiente favorável ao seu desenvolvimento, até atingir as características adequadas para sobreviver. No contexto econômico, as incubadoras podem ser pensadas como nos exemplos acima, já que surgem como um instrumento de proteção e apoio às Micro e Pequenas Empresas.

Fonseca e Kruglianskas (2000) argumentam que a essência das incubadoras, está voltada para a impulsão de novos negócios. As incubadoras devem dispor de infraestrutura, disponibilizar treinamentos, recursos humanos, assessorias e consultorias com serviços especializados que auxiliem as empresas residentes em suas atividades, como elaboração de plano de negócios, gestão empresarial, gestão da inovação tecnológica, engenharia de produção, contabilidade, marketing, assistência jurídica, captação de recursos e acesso a mecanismos de financiamento (ANPROTEC/SEBRAE, 2002; EUROPEAN COMMISSION, 2002; HACKETT e DILTS, 2004; CELTA, 2007).

As Incubadoras, em geral, oferecem aos empreendedores em potencial um ambiente flexível e encorajador, com apoio em infraestrutura física (salas, laboratórios, auditórios, bibliotecas, etc.) e suporte empresarial nas diversas áreas (consultoria, capacitação, estratégia, marketing, finanças, tecnologia, jurídica, contábil, RH, entre outras) (MARTINS et al., 2005, p. 2).

Na literatura específica da área, as incubadoras possuem diferentes classificações e estruturas. De acordo a Anprotec (2015):

Existem diversos tipos de incubadoras: as de base tecnológica (abrigam empreendimentos que utilizam tecnologias); as tradicionais (dão suporte a empresas de setores tradicionais da economia); as mistas (aceitam tanto empreendimentos de base tecnológica, quanto de setores tradicionais) e as sociais (que têm como público-alvo cooperativas e associações populares) (ANPROTEC, 2015).

Segundo Souza et al. (2003):

O projeto das ITCPs foi inspirado pelo movimento em prol da cidadania contra a fome e a miséria, liderado por Betinho (1992), que lançou uma semente no pensamento solidário. A consciência de que a ação de distribuir alimentos teria que ser ampliada com iniciativas visando gerar trabalho e renda fez com que professores da Fundação Oswaldo Cruz (Fiocruz) em parceria com a Universidade de Santa Maria, no Rio Grande do Sul, criassem uma cooperativa popular, formada por moradores da região da Maré - RJ, que pudesse prestar serviços para a própria Fiocruz, surgindo dessa forma a Cooperativa de Manguinhos. A experiência bem-sucedida de Manguinhos fez com que professores e alunos da Engenharia da UFRJ (Coppe - Coordenação de Programas de Pós-graduação da engenharia) decidissem criar, em 1995, a primeira iniciativa de uma Incubadora Tecnológica de Cooperativas Populares, cujo objetivo inicial foi estabelecer um contato com comunidades das favelas interessadas na formação de cooperativas de trabalho (SOUZA et al., 2003).

A partir da análise de diferentes experiências, Jordan (1974) identificou que todas as formas de incubação se configuram como um sistema interligado, constituído de elementos (entidades) com interação e interdependência regular, formando um todo integral. 
Durante a incubação o empreendimento incubado é acompanhado pela equipe multidisciplinar da incubadora, que trabalha no intuito de poder organizá-la gerencialmente e, com isso, melhorar suas chances de sucesso e permanência no mercado. O período é dividido em três fases: pré-incubação, incubação e desincubação.

(i) A pré-incubação é o período no qual ocorre o processo de formação e institucionalização da incubadora. É conhecida como processo inicial que permite suporte para as demais fases de incubação dos empreendimentos dentro de uma incubadora. A pré-incubação representa a fase de organização estrutural da equipe da incubadora e a construção dos objetivos presentes no processo formação do conhecimento necessário para o alcance do resultado final.

(ii) A incubação é tida como o período de tempo em que as incubadas receberão apoio da incubadora em diversas áreas do conhecimento, de modo a facilitar os processos produtivos de trabalho das mesmas. Pode ser denominada como a etapa que a equipe da incubadora realizará assistência, visando à construção de melhores chances para o seu sucesso e permanência do mercado (ANPROTEC, 2002). Durante a incubação são realizadas atividades visando o fomento de diversas áreas administrativas. Desse ponto, podem ser tratados pontos de estratégia importante, como o princípio de autogestão, modelo de gestão corriqueiro em empreendimentos solidários.

(iii) A desincubação atua no desligamento do grupo social do projeto de incubação. Isso poderá ser um processo lento e gradativo, pois os fatores que interferem nessa etapa do andamento da trajetória devem ser analisados de forma concreta, podendo gerar a visualização dos pontos fortes do empreendimento. Conforme destaca Dornelas (2002), o processo de desincubação começa após o término do período de consolidação e pode compreender um período de até seis meses, dependendo do grau de adesão da preparação para a "graduação e saída da incubadora".

O mapeamento das incubadoras, presentes na região sul do Brasil, torna-se importante, para o reconhecimento das atividades desenvolvidas, bem como, a identificação dos modelos de incubação propostos por essas incubadoras. A ampliação do leque de conhecimentos, sobre as incubadoras é vista como uma clara oportunidade a ser explorada, com benefícios potenciais, tanto para os bancos de dados, como também, para as demais incubadoras presentes em outras regiões no país, garantindo assim, a melhor visualização das práticas que obtiveram sucesso e dos desafios enfrentados no âmbito organizacional (JAYO e DINIZ, 2013 apud BOTELHO et al., 2015).

\section{Metodologia}

A presente seção tem por objetivo apresentar os procedimentos metodológicos que guiaram esta investigação, construindo um panorama conceitual sobre a atuação das ITCPs na região sul do Brasil. Nesse sentido, apresenta-se a questão de pesquisa: Quais ITCPs são encontradas na Região Sul do Brasil, como se dá a sua atuação na região e quais as principais dificuldades enfrentadas pelas ITCPs e pelos empreendimentos incubados?

Segundo Morgan (2002), os estudos organizacionais podem pautar-se em quatro paradigmas: o funcionalista, o interpretativista, o humanista radial e o estruturalista radical. Quanto ao delineamento adotado no estudo, optou-se pela utilização do paradigma funcionalista, pois este se fundamenta no olhar objetivo da realidade pesquisada. Para Morgan (2002, p. 16), o paradigma funcionalista "se baseia na pressuposição de que a sociedade tem existência concreta e real e um caráter sistêmico orientado para produzir um estado de coisas ordenado e regulado". Assim, as pesquisas orientadas pelo funcionalismo são reguladoras e práticas, visam a produção de conhecimento empírico útil, o que se aplica ao presente estudo.

A pesquisa é quantitativa e seguiu a sugestão de Merriam (1998) para amostragem em pesquisas quantitativas. A amostra precisou de um procedimento de seleção dos elementos ou grupo de elementos, de modo que dá a cada elemento uma probabilidade de inclusão (FULGENCIO, 2009).

Para estabelecer a amostra da pesquisa (Quadro 1), utilizou-se o recorte geográfico como forma de seleção de ITCPs, sendo escolhidos para análise os seguintes estados: Paraná (um investigado), Santa Catarina (três investigados) e Rio Grande do Sul (sete investigados). É importante definir previamente a área geográfica que o estudo deverá cobrir, pois isso trará impactos sobre a definição da amostra (YIN, 1999). 
Quadro 1 - Relação das incubadoras mapeadas na Região Sul do Brasil

\begin{tabular}{|c|c|c|}
\hline \multicolumn{3}{|c|}{ INCUBADORAS DA REGIÃO SUL DO BRASIL } \\
\hline Incubadoras & Instituição de Ensino Vinculada & Estado \\
\hline $\begin{array}{l}\text { Incubadora Tecnológica de } \\
\text { Cooperativas Populares - ITCP }\end{array}$ & Universidade Federal do Paraná - UFPR & Paraná \\
\hline $\begin{array}{l}\text { Incubadora Tecnológica de } \\
\text { Cooperativas Populares }\end{array}$ & Universidade do Sul de Santa Catarina - Unisul & Santa Catarina \\
\hline $\begin{array}{l}\text { Incubadora Tecnológica de } \\
\text { Cooperativas Populares }\end{array}$ & Universidade do Vale do Itajaí - UNIVALI & Santa Catarina \\
\hline $\begin{array}{l}\text { Incubadora Tecnológica de } \\
\text { Cooperativas Populares - ITCP }\end{array}$ & Unochapecó & Santa Catarina \\
\hline $\begin{array}{l}\text { Incubadora Tecnológica de } \\
\text { Cooperativas Populares da } \\
\text { Universidade Federal do } \\
\text { Rio Grande do Sul - ITCP UFRGS }\end{array}$ & Universidade Federal do Rio Grande do Sul - UFRGS & Rio Grande do Sul \\
\hline $\begin{array}{l}\text { ITECSOL - Incubadora de } \\
\text { Tecnologia Social e Economia } \\
\text { Solidária }\end{array}$ & Universidade Regional do Noroeste do UNIJUI & Rio Grande do Sul \\
\hline $\begin{array}{l}\text { Incubadora de Empreendimentos } \\
\text { Solidários e Tecnologia Social } \\
\text { do Rio Grande do Sul - PUCRS }\end{array}$ & Pontifícia Universidade Católica & Rio Grande do Sul \\
\hline $\begin{array}{l}\text { Incubadora de Empreendimentos } \\
\text { Solidários do Unilasalle }\end{array}$ & Centro Universitário La Salle - Canoas & Rio Grande do Sul \\
\hline $\begin{array}{l}\text { Incubadora Tecnossocial de } \\
\text { Cooperativas e Empreendimentos } \\
\text { Econômicos Solidários - ITCEES da }\end{array}$ & $\begin{array}{l}\text { Universidade Federal da Fronteira Sul } \\
\text { campus Cerro Largo - UFFS }\end{array}$ & Rio Grande do Sul \\
\hline Incubadora Social da UFSM & Universidade Federal de Santa Maria - UFSM & Rio Grande do Sul \\
\hline $\begin{array}{l}\text { Programa Tecnologias Sociais } \\
\text { para Empreendimentos Solidários } \\
\text { - TECNOSOCIAIS }\end{array}$ & Universidade do Vale do Rio dos Sinos - UNISINOS & Rio Grande do Sul \\
\hline
\end{tabular}

Fonte: Elaborada pelos autores, 2015.

Em relação a estratégia de pesquisa, adotou-se o estudo de caso. Merriam (1998) argumenta que no estudo de caso o interesse está no processo e não nos resultados, como é o caso desta pesquisa. A autora expõe, ainda, que a importância desse procedimento está no contexto e não numa variável específica.

Com base na escolha dos investigados, iniciou-se a pesquisa de campo, tendo como ponto de partida contato, por telefone e e-mail com cada coordenador de ITCP investigada. Após esse contato, enviou-se o Termo de Consentimento Livre e Esclarecido, junto do questionário, por e-mail para cada coordenador de ITCP. Todo esse processo foi realizado nos meses de maio, junho e julho de 2015.

O questionário enviado aos coordenadores das ITCPs é composto por questões fechadas e construído em três blocos temáticos, a fim de obedecer uma ordem lógica na elaboração das perguntas. São os blocos temáticos do questionário: (i) No que se refere ao perfil de atuação da incubadora; (ii) No que se refere ao processo de incubação; e (iii) No que se refere ao perfil dos empreendimentos incubados.

Os dados da pesquisa foram coletados a partir do questionário e de dados secundários (documentais) extraídos das ITCPs, como dos sítios web, publicações, livros, documentos da Rede de ITCPs, entre outros.

\section{Análise dos Dados}

Os dados foram processados em uma Planilha Calc do software livre da LibreOffice.

\section{Resultados e Discussão}

Baseando-se nas respostas do questionário aplicado, nesta seção, apresenta-se um panorama das ITCPs entrevistadas, bem como, os principais problemas e ou desafios enfrentados por elas ao longo do tempo. 


\section{ITCP do Paraná}

A Incubadora Tecnológica de Cooperativas Populares da UFPR se caracteriza como um "programa de educação, extensão e pesquisa universitária, vinculado à Coordenadoria de Desenvolvimento Social - CDS, órgão subjacente à Pró-Reitoria de Extensão e Cultura - PROEC/UFPR". Possui uma equipe composta de trinta e duas pessoas, entre bolsistas e professores, com três empreendimentos incubados, atuante desde 1998. Os empreendimentos possuem poucas informações disponíveis sobre o mercado local, assim o apoio gerencial prestado pela incubadora torna-se importante para o gestor desenvolver o empreendimento. Também, os empreendimentos possuem muita dificuldade em obter mão de obra qualificada e acessível economicamente, em conseguir financiamentos, em desenvolver novos produtos e vendê-los, além do mercado local possuir baixa viabilidade econômica. Atua em comunidades e empreendimentos com princípios voltados à cooperação, associativismo e economia solidária, focando em comunidades rurais (ITCP - UFPR, 2015).

\section{ITCPs de Santa Catarina}

A Incubadora Tecnológica de Cooperativas Populares da Unisul é um programa que funciona há quatorze meses e possui uma equipe com sete integrantes, formada por bolsistas e professores. A incubadora social abriga mais de seis empreendimentos, que apresentam dificuldades para conseguir mão de obra qualificada a custo adequado, obter financiamentos e desenvolver novos produtos. Atua como um programa que socializa o conhecimento acadêmico com a realidade local e regional, visando "apoiar, auxiliar e assessorar iniciativas de economia solidária, por meio do fomento de cooperativismo e autogestão dos grupos organizados, articulando com a gestão pública estratégias e ações voltadas a inclusão social" (ITCP - UNISUL, 2015).

A Incubadora Tecnológica de Cooperativas Populares da Univali é um Programa Permanente de Extensão Universitária, vinculada à reitoria de pós-graduação de pesquisa, extensão e cultura, que possui sete anos de existência, tem quinze integrantes (bolsistas e professores) e incuba mais de seis empreendimentos. A maior dificuldade enfrentada pelos empreendimentos é conseguir financiamento, necessitando de toda ajuda que a incubadora puder ofertar. Não apresentam nenhuma dificuldade em encontrar mão de obra qualificada e em conta. Atua visando "promover a inserção na economia formal de grupos sociais excluídos ou em processo de exclusão, a partir da organização para o trabalho, através da incubação e acompanhamento de empreendimentos de economia solidária" (ITCP - UNIVALI, 2015).

A Incubadora Tecnológica de Cooperativas Populares da Unochapecó é um projeto vinculado à Vice-reitoria de Pesquisa, Ensino e Extensão, possui doze anos de funcionamento e conta com uma equipe de dez pessoas, dividida em professores, técnicos, bolsistas de graduação, pós e voluntários. Incuba mais de seis empreendimentos que não possuem informações suficientes sobre o mercado local, a fim de melhorar o seu gerenciamento. Os empreendimentos encontram mais dificuldade em obterem financiamento e venderem seus produtos, além do mercado local apresentar baixa viabilidade econômica. Atua com o objetivo de "contribuir para o cumprimento da função social da universidade, compreendida enquanto produção e difusão de conhecimento voltado às demandas da sociedade, prioritariamente de grupos sociais excluídos" (ITCP UNOCHAPECÓ, 2015).

\section{ITCPs do Rio Grande do Sul}

A Incubadora Tecnológica de Cooperativas Populares da UFRGS nasce como Núcleo de Economia Solidária ligada às atividades de extensão da UFRGS. É uma incubadora tecnológica com quinze anos de funcionamento e que, atualmente, conta com dezesseis integrantes, divididos em bolsistas e professores. Incuba mais de seis empreendimentos, que possuem dificuldade para conseguir financiamento e custear mão de obra qualificada para efetuar seus serviços, assim como para desenvolver e vender novos produtos, além do mercado local apresentar baixa viabilidade econômica. Atua no "diagnóstico, estudo de viabilidade financeira, planejamento estratégico, assessoria contábil, formação de preços, design, comunicação, legislação e formação permanente em economia solidária" (ITCP - UFRGS, 2015).

A ITECSOL/UNIJUÍ além de ser uma unidade administrativa ligada a Agência de Inovação e Tecnologia da Unijuí, é um projeto de extensão com características interdisciplinar e interdepartamental, 
que conta com dez anos de funcionamento. Sua equipe, atualmente, é composta de dezessete integrantes (bolsistas e professores), incubando mais de seis empreendimentos, que possuem maior dificuldade em obter financiamento e desenvolver novos produtos, afetando seu bom e contínuo funcionamento. "Atua no sentido de contribuir na implementação de condições para a organização dos trabalhadores, em processos coletivos de geração de trabalho e renda, tendo como referência o movimento de economia solidária" (ITECSOL - UNIJUÍ, 2015).

A Incubadora de Empreendimentos Solidários e Tecnologia Social da PUCRS se configura como programa de extensão da universidade, vinculada a Pró-Reitoria de Extensão. Tem três anos de funcionamento, conta com uma equipe de dez pessoas, divididos entre alunos bolsistas e técnicos, e incuba mais seis empreendimentos, visando fortalecer formas associativas econômicas solidárias para qualificação dos seus processos produtivos identificando e aprimorando tecnologias sociais, utilizadas com vistas ao desenvolvimento sustentável regional (INCUBADORA DE EMPREENDIMENTOS SOLIDÁRIOS E TECNOLOGIA SOCIAL - PUCRS, 2015). No geral, os empreendimentos não possuem informações suficientes sobre o mercado local, apresentam muita dificuldade em desenvolver e vender seus produtos, obter financiamento, mão de obra qualificada e o mercado local apresenta baixa viabilidade econômica.

A Incubadora de Empreendimentos Solidários da UNILASALLE Canoas foi constituída há sete anos com o objetivo de contribuir para a consolidação de empreendimentos de economia solidária bem como redes de cooperação no município de Canoas e região, na perspectiva de construir tecnologias sociais apropriadas para fortalecer a capacidade empreendedora e a dinâmica solidária, potencializando sua atuação sustentável e autogestionária nos territórios onde atuam. É um "projeto dentro do Tecnosocial Unilasalle, essa estrutura envolve outros projetos que visam o desenvolvimento dos territórios, o fortalecimento da economia solidária, bem como outras ações da esfera pública" (INCUBADORA DE EMPREENDIMENTOS SOLIDÁRIOS - UNILASALLE CANOAS, 2015). Conta com uma equipe de sete pessoas, formada por bolsistas e professores e incuba mais de seis empreendimentos, que sentem dificuldade em obter informações sobre o mercado local, em conseguir financiamento, desenvolver novos produtos e vendê-los, principalmente logo que chegam na incubadora.

A ITCEES da UFFS é um laboratório, vinculado ao Campus Cerro Largo (RS) da Universidade Federal da Fronteira Sul (UFFS), que desenvolve atividades de pesquisa e extensão voltadas para o estímulo de iniciativas de economia solidária. Foi fundada há um ano e oito meses e conta com uma equipe de quatorze pessoas, divididas entre bolsistas e professores. Incuba dois empreendimentos, que enfrentam maiores dificuldades em obter informações sobre o mercado local, a fim de comercializarem seus produtos. As ações da ITCEES estão voltadas para trabalhadores desempregados ou inseridos nas informalidades localizadas geograficamente na região de abrangência do Campus de Cerro Largo, sendo: Missões, Celeiro, Noroeste Colonial e Fronteira Noroeste. Sua atuação está pautada no atendimento prioritário de demandas oriundas de associações de bairros, sindicatos, cooperativas de trabalhadores, escolas públicas e demais formas de organizações sociais representativas da sociedade civil.

A Incubadora Social da UFSM afirma-se como um programa de extensão universitária de relevância social, por meio da Pró-Reitoria de Extensão da Universidade. É composta por uma equipe de quatro integrantes, entre bolsistas e professores, com três anos de funcionamento. Estão incubados cinco empreendimentos voltados a agricultura familiar e ao artesanato, que têm dificuldade em conseguirem mão de obra qualificada com custo acessível e financiamentos; desenvolverem novos produtos e vendê-los; e, ainda, o mercado local possui baixa viabilidade econômica. Atua no desenvolvimento regional, apoiando novos empreendedores, de forma comprometida com a realidade social (ITSM - UFSM, 2015).

O TECNOSOCIAIS da UNISINOS é um programa que possui dez anos de funcionamento como incubadora tecnossocial. Conta com quatro integrantes, divididos em bolsistas e técnicos. Incuba três empreendimentos ligados à economia solidária, cooperativismo e reciclagem. Atua voltando-se às:

“[...] definições estratégicas da Universidade no que diz respeito à inserção regional - dado que possibilita a contribuição da UNISINOS na construção de espaços produtivos construídos na perspectiva do desenvolvimento humano e sustentável -, bem como do ponto de vista da produção interdisciplinar de conhecimentos, que é da própria natureza do trabalho proposto" (TECNOSOCIAIS UNISINOS, 2015). 


\section{Panorama Geral das ITCPs}

No quadro abaixo, temos a relação de cada uma das ITCPs entrevistadas, das áreas de atuação dos empreendimentos incubados e das etapas de incubação realizadas pelas ITCPs. Pode-se notar a similaridade entre as atividades desenvolvidas pelos incubados e como ela aumenta dentro de cada estado analisado. Deve-se levar em conta a região onde estão inseridas essas ITCPs e sua área de abrangência, pois é determinante no tipo de empreendimento e sua área de atuação. Segundo Fraga (2012), as incubadoras, geralmente, atuam a partir da universidade, gerando aprendizagem e fica evidente como a maioria delas vêm de contexto acadêmico. Assim, sua ação é mais que prestar assistência aos empreendimentos, é também inovar, fazendo as regiões de abrangência das ITCPs ousarem com novas atividades, novos serviços e novas formas de operação, produzindo novos conhecimentos.

Quadro 2 - Relação das incubadoras mapeadas na Região Sul do Brasil e área de atuação

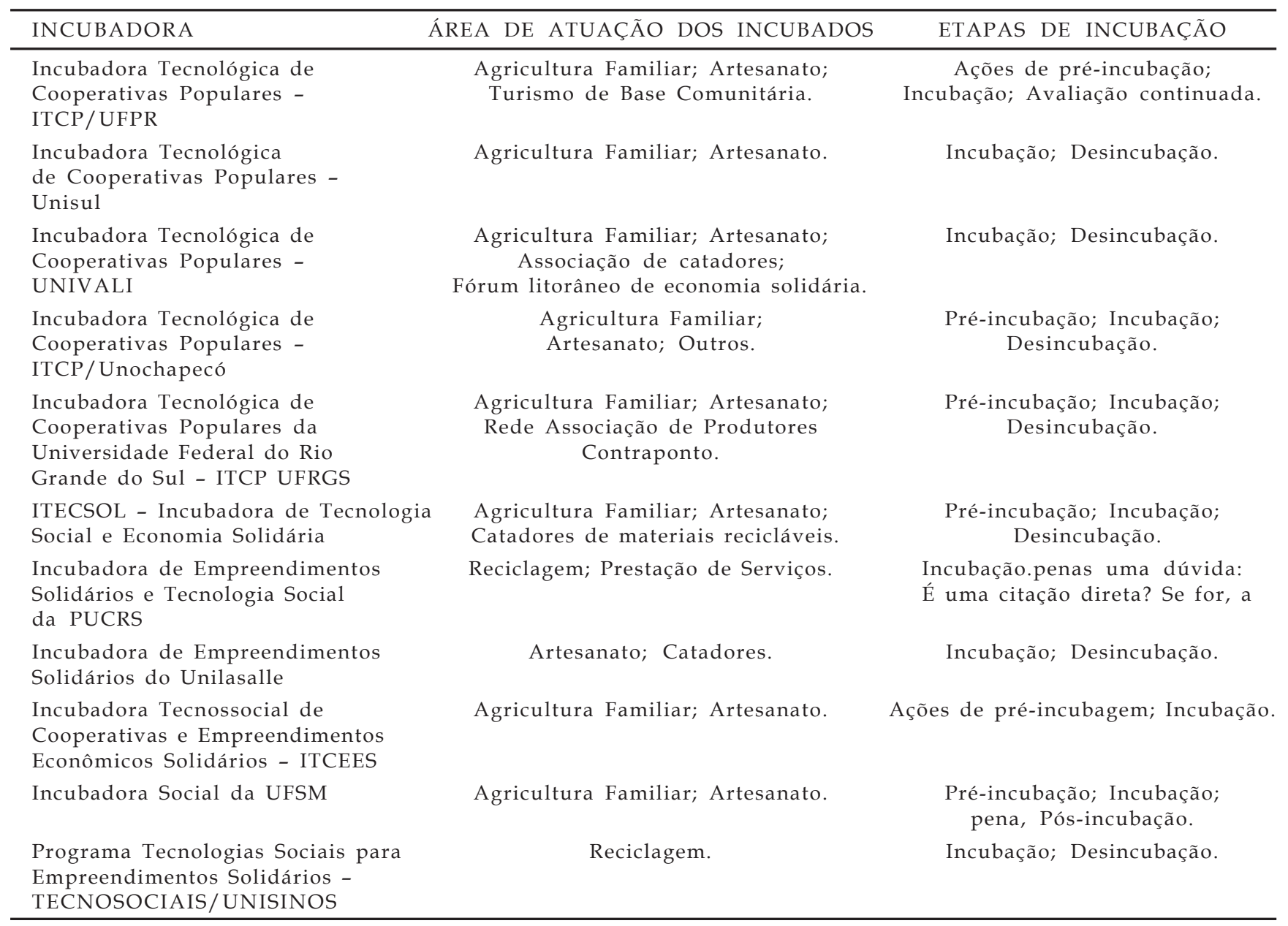

Fonte: Elaborado pelos autores, 2015.

Sabe-se que muito foi feito nos últimos anos, em relação ao incentivo do governo federal na criação de políticas públicas voltadas às ITCPs. É possível associar a idade das incubadoras com a criação do Proninc (Programa Nacional de Incubadoras Tecnológicas de Cooperativas Populares), fundado em 1998 e revivido em 2003, por meio da Senaes, peça chave no desenvolvimento das ITCPs.

A Secretaria Nacional de Economia Solidária (Senaes) surgiu em 2003, num momento em que a economia solidária estava entrando numa fase de crescente reconhecimento público e incipiente institucionalização. Ela havia começado a tomar corpo na primeira metade dos anos 1990, com a multiplicação das empresas recuperadas (frutos da desindustrialização e do desemprego em massa), das cooperativas nos assentamentos de reforma agrária, das cooperativas populares nas periferias metropolitanas, formadas com o auxílio de incubadoras universitárias e dos Projetos Alternativos Comunitários (PACs) semeados pela Cáritas nos bolsões de pobreza dos quatro cantos do Brasil (SINGER, 2009, p. 43). 
Atualmente, o Proninc apoia mais de quarenta incubadoras em todo território nacional e seu objetivo é ajudar "na consolidação e ampliação das incubadoras, de modo a favorecer a criação e o acompanhamento de novos empreendimentos solidários, principalmente através do fortalecimento das incubadoras" (PRONINC, 2015).

As ITCPs oriundas de universidades conseguem operar, prioritariamente, graças aos editais de instituições e programas ligados ao governo (CNPq, ProExt, outros), responsáveis pelo custeio de projetos que trazem os recursos financeiros necessários às incubadoras para manterem seus bolsistas, auxiliarem os empreendimentos incubados e gerarem novos conhecimentos, integrando ensino, pesquisa e extensão. Apesar de suas particularidades, a maioria das incubadoras surge por intermédio de professores, funcionários e estudantes, ligados aos grupos populares, geralmente público-alvo da incubação.

Porém, vive-se um momento delicado para a economia solidária, sentido fortemente pelas ITCPs, ambas diretamente ligadas. Os editais que ajudam a manter as incubadoras não estão oferecendo ajuda financeira suficiente para que todas as ITCPs funcionem normalmente, algumas delas não contam com recurso algum. Com isso, essas incubadoras perderam parte de sua equipe, pois eles não conseguem manter-se sem as bolsas. O bom andamento da incubadora é comprometido e, consequentemente, os empreendimentos que dependem delas, são comprometidos também, assim como as pessoas dependentes desses empreendimentos.

Fraga (2012) faz uma análise sobre a atuação das incubadoras: "os trabalhadores dos grupos populares incubados são também os mesmos que não têm condições dignas de moradia, de acesso à saúde, educação e serviços básicos, como saneamento e coleta de lixo". Sendo assim, fica claro que as incubadoras, tão dependentes de recursos, muitas vezes, insuficientes, não conseguem sanar problemas de ordem tão complexa, tornando evidente a sua limitação na resolução desses problemas e levantando dúvidas no público externo, acerca da sua credibilidade como instrumento de ajuda e aprendizagem da universidade para com a comunidade externa.

Outro problema enfrentado pelas incubadoras universitárias, comumente mais jovens, é a baixa autonomia para tomar decisões, como a escolha dos empreendimentos à serem incubados e lançamentos de editais de seleção. Nas ITCPs mais antigas, esse vínculo com a universidade é contornado por meio de ações que descentralizam o poder da instituição em relação às incubadoras, porém, para as ITCPs mais recentes, oriundas de novas universidades, a dependência é alta, atrasando suas atividades e demandando de grande energia para que tudo corra conforme as normas que regem essa universidade.

Fazer parte de uma incubadora é estar ligado a uma economia com o escopo diferente das demais. Por mais que o seu intuito seja ajudar empreendimentos a se manterem e se consolidarem, seus princípios não visam geração de lucro, mas sim geração de conhecimento. A economia solidária é, hoje, muito mais popular do que há anos, antes das leis de incentivo a ela, entretanto, deve-se cuidar para não apagar o caminho trilhado por políticas alheias a sua importância e conceitos equivocados. Essa é uma grande preocupação dentro da Rede de ITCPs, pois sua luta é árdua e suas conquistas sofridas e demoradas, a fim de que a economia solidária seja reconhecida como economia de fato, capaz de trazer desenvolvimento e reconhecimento para aqueles que vivem dela.

\section{Considerações Finais}

O presente trabalho teve como objetivo identificar algumas das Incubadoras Tecnológicas de Cooperativas Populares (ITCPs) na região sul do Brasil, fazendo uma rápida análise das suas atuações regionais, a fim de conhecer os principais problemas enfrentados pelos empreendimentos e os pontos fortes de assessoramento dessas incubadoras, de acordo com sua linha de atuação. Assim, foram encaminhados questionários, junto dos termos de consentimento livre e esclarecidos, para onze ITCPs da região Sul do país, composta pelos estados: Paraná, Rio Grande do Sul e Santa Catarina.

No estado do Paraná, segundo o IPARDES (2015) (Instituto Paranaense de Desenvolvimento Econômico e Social), a agropecuária e a indústria são as principais atividades econômicas. Nos empreendimentos incubados pela ITCP, nota-se a mesma tendência de atividades. Em Santa Catarina, os empreendimentos incubados ligam-se a economia solidária e ao cooperativismo, com atividades econômicas voltadas à agricultura familiar e ao artesanato. Por fim, no estado do Rio Grande do Sul, percebeu-se o predomínio nos empreendimentos incubados das atividades ligadas à agricultura familiar e ao artesanato, nas sete incubadoras entrevistadas. Isso se dá, muito pelo fato do estado ter a economia, predominantemente, voltada à agropecuária, com ênfase nas pequenas propriedades rurais. Seu cenário é propício para a linha de incubadoras tecnossociais e sociais. 
No geral, a maioria das incubadoras investigadas incubam empreendimentos voltados ao artesanato e à agricultura familiar, podendo mencionar-se também os catadores, isto é, são empreendimentos mantidos por meio dos princípios da economia solidária e do cooperativismo, que regem, de maneira geral, o trabalho de grande parte das ITCPs. Essas atividades desempenhadas pelos empreendimentos incubados nas ITCPs do Sul do Brasil, são a força motriz da economia solidária da região, notando-se a sua importância na manutenção desse ramo da economia.

A maioria das incubadoras tem sua metodologia de incubação estruturada em três fases bem definidas: pré-incubação, incubação e desincubação. Muitas das incubadoras que não apresentam as três fases, acabam desenvolvendo-as de outra maneira (mesclando as fases) e, algumas das ITCPs, por serem muito jovens, não contam com todas as fases de incubação implementadas. A necessidade da criação de parâmetros para a percepção do grau de maturidade das incubadas torna-se importante para a avaliação, de forma geral, por parte das ITCPs, do processo de incubação, bem como, dos benefícios empregados aos incubados, já alcançados pelo período de incubação.

Diante do estudo informado, percebe-se que as ITCPs presentes na região sul do país, estabelecem suas atividades voltadas ao atendimento de empreendimentos de origem solidária ou interligados com movimentos sociais. As ITCPS, em sua maioria, encontram-se vinculadas a instituições de ensino superior. Desse modo, estabelecem um cenário propício ao desenvolvimento regional, levando em consideração o papel educativo das incubadoras e buscando soluções que aliem a tradição econômica às novas alternativas, tudo isso em virtude do assessoramento prestado pelas mesmas aos empreendimentos atendidos.

Então, pôde-se concluir que a presença das incubadoras na região Sul do país tem forte participação do PRONINC, como apoiador e fomentador de suas ações voltadas à economia solidária. As ITCPs apresentam características próprias, mas voltam-se ao assessoramento dos empreendimentos incubados, para qualificá-los e fortalecê-los, apoiando e estruturando uma economia diferente da convencional, com muitos obstáculos, mas com boas perspectivas de futuro, atraindo o interesse cada vez maior por parte de empreendimentos, com relação à participação e incubação nas ITCPs, fortalecendo a Região Sul e incentivando a diversificação da economia, para que não haja dependência em relação as atividades desenvolvidas, minimizando eventuais dificuldades a serem enfrentadas.

\section{Referências Bibliográficas}

ANPROTEC. Associação Nacional de Entidades Promotoras de Empreendimentos de Tecnologias Avançadas. Incubadora de empresas. Disponível em: < http://www.anprotec.org.br/ anprotec.htm\#5 >. Acesso em: jul. 2015.

ANPROTEC/SEBRAE. Glossário dinâmico de termos na área de Tecnópolis, Parques Tecnológicos e Incubadoras de Empresas. Brasília, 2002.

BEZERRA, A. F.A.; SILVA, W. S. C.; CARVALHO, Z. V. As Incubadoras Sociais e o Desenvolvimento Local: O que é e porque apoiar a iniciativa. In: Seminário Nacional de Parques Tecnológicos e Incubadoras de Empresas, 23., 2013, Recife. Anais... Recife, PE, 2013.

BOTELHO, L. L. R.; LIMA, D. F.; BRAUN, J. C. A.; WUERGES, A. F. E.; GAUTHIER, F. A. O.; NOGUEIRA, S. V. Incubadoras tecnológicas de cooperativas populares: atuando a partir da extensão universitária. In: XV COLÓQUIO INTERNACIONAL DE GESTÃO UNIVERSITÁRIA CIGU, 2015, Argentina. Anais... Argentina: CIGU, 2015.

CELTA - Centro Empresarial para Laboração de Tecnologias Avançadas. Informações 2007. Disponível em: <www.celta.com.br>. Acesso em: nov. 2014.

DORNELAS, J. Planejando Incubadoras de Empresas: Como Desenvolver um plano de Negócios para Incubadoras. Rio de Janeiro: Campus Ltda, 2002.

EUROPEAN COMMISSION ENTERPRISE DIRECTORATE-GENERAL. Benchmarking of business incubators - final report. Sevenoaks: Center for Strategy \& Evaluation Services, 2002.

FONSECA, S. A.; KRUGLIANSKAS, I. Avaliação do desempenho de incubadoras empresariais mistas: um estudo de caso no Estado de São Paulo, Brasil. In: CONFERÊNCIA LATINO-AMERICANA DE PARQUES TECNOLÓGICOS E INCUBADORAS DE EMPRESAS, 2000, Panamá. Anais... Panamá: IASP, 2000. 
FRAGA, L. S. Extensão e transferência de conhecimento: As incubadoras Tecnológicas de Cooperativas Populares. Tese de Doutorado, Universidade Estadual de Campinas, Campinas, SP, Brasil, 2012.

FULGENCIO, P. C. Glossario - Vade Mecum. Mauad Editora Ltda; p. 46, 2009.

HACKETT, S. M.; DILTS, D. M. A systematic review of business incubation research. Journal of Technology Transfer, Netherlands, v.29, n.1, p. 55-82, 2004.

INCUBADORA DE EMPREENDIMENTOS SOLIDÁRIOS - UNILASALLE CANOAS. Disponível em: < http://www.unilasalle.edu.br/canoas/tecnosocial/ >. Acesso em: 16 jun. 2015.

INCUBADORA DE EMPREENDIMENTOS SOLIDÁRIOS E TECNOLOGIA SOCIAL - PUCRS. Disponível em: < https://incubadorasocialpucrs.wordpress.com/about/ >. Acesso em: 22 jun. 2015.

IPARDES (2015). Instituto de Paranaense de Desenvolvimento Econômico e Social. Disponível em: < http:/ /www.ipardes.gov.br/index.php?pg_conteudo=1\&cod_conteudo=1 >. Acesso em: 15 jul. 2015.

ITCP - UFPR. Incubadora Tecnológica de Cooperativas Populares da UFPR. Disponível em: < http:/ /www.itcp.ufpr.br/ >. Acesso em: 23 jun. 2015.

ITCP - UFRGS. Incubadora Tecnológica de Cooperativas Populares da UFRGS. Disponível em: < http://www.itcp.coppe.ufrj.br/ridi/itcpufrgr.html >. Acesso em: 21 jun. 2015.

ITCP - UNISUL. Incubadora Tecnológica de Cooperativas Populares. Disponível em: < https:// www.facebook.com/itcpunisul/info?tab=page_info >. Acesso em: 23 jun. 2015.

ITCP - UNIVALI. Incubadora Tecnológica de Cooperativas Populares. Disponível em: < http:// www.univali.br/ensino/graduacao/cejurps/cursos/direito/direito-itajai/extensao-e-cultura/ observatorio-de-politicas-publicas/incubadora-tecnologica-de-cooperativas-populares-da-univaliitcp/Paginas/default.aspx >. Acesso em: 16 jun.2015.

ITCP - UNOCHAPECÓ. Incubadora Tecnológica de Cooperativas Populares. Disponível em: < http:/ / unochapeco.edu.br/incubadora-tecnologica-de-cooperitivas-populares >. Acesso em: 17 de jun.2015.

ITECSOL - UNIJUÍ. Incubadora de Economia Solidária, Desenvolvimento e Tecnologia Social. Disponível em: < http://www.projetos.unijui.edu.br/cidadania/itecsol/index.php/menu-itecsol/ a-incubadora $>$. Acesso em: 16 jun.2015.

ITSM - UFSM. Incubadora Tecnológica de Santa Maria. Disponível em: < http://coral.ufsm.br/itsm/ index.php/itsm >. Acesso em: 16 jun.2015.

JAYO, M.; DINIZ, E. Um mapeamento descritivo dos modelos de gestão de redes de correspondentes bancários no Brasil. Revista de Administração da Universidade de São Paulo (RAUSP), São Paulo, v.48, n.3, p. 621-634, 2013.

JORDAN, N. Temas de Psicología Especulativa. Buenos Aires: Troquel S.A, 1974.

MARTINS, G. S.; LIMA, A. A. T. F. C.; SANTOS, C. A.; OLIVEIRA, A. R.; CARVALHO, R. M. M. A.; GOMES, R. C. Incubadoras de Base Tecnológica: um estudo sobre a Capacitação Gerencial no Processo de Incubação. In: ENCONTRO DA ASSOCIAÇÃO NACIONAL DE PÓS-GRADUAÇÃO E PESQUISA EM ADMINISTRAÇÃO, 29., 2005, Brasília. Anais... Brasília, DF, Brasil, 2005.

MERRIAM, S. Qualitative Research and Case Study Applications in Education. SanFrancisco: Jossey-Bass, 1998.

MORGAN, G. Paradigmas, metáforas e resolução de quebra-cabeças na teoria das organizações. In: CALDAS, M.P.; BERTERO, C.O. (Orgs). Teoria das organizações: série RAE-clássicos. São Paulo: Atlas, 2007, p.12-33

PIMENTEL, T. A. B.; OliveirA, L. G. L.; REINALDO, H. O. A. Análise das dimensões de empreendedorismo sustentável em micro, pequenas e médias indústrias no Ceará. Revista REUNA, v. 17, n. 4, p. 85-104, 2012. 
PRONINC. Ministério do Trabalho e Emprego. 2015. Disponível em: < http://portal.mte.gov.br/ ecosolidaria/proninc.htm >. Acesso em: 15 jul.2015.

SINGER, P. Políticas públicas da secretaria nacional de economia solidária do Ministério de Trabalho e Emprego. Mercado de Trabalho, 39, 43-48. 2009.

SOUZA, M. C. A. F.; AZEVEDO, A.; OLIVEIRA, L. J. R.; BALDEON, N. T. Incubadora tecnológica de cooperativas - ITCP X Incubadora de base tecnológica - IEBT: Diferenças e semelhanças no processo de incubação. Revista Iboamericana de Ciência, Tecnologia, Sociedade e Inovação, n. 6, 2003.

TECNOSOCIAIS UNISINOS. Disponível em: < http://ihu.unisinos.br/areas/trabalho/52-tecnosociais $>$. Acesso em: 22 jun2015.

YIN, R. K. Estudo de caso: planejamento e métodos (2a ed.). Porto Alegre: Bookman. 1999.

ZOUAIN, D. M.; TORRES, L. S. A suposta modernização das relações de trabalho nas incubadoras de empreendimentos. Cadernos EBAPE.BR, v. 3, ed. especial, p. 01-07, 2005.

\footnotetext{
${ }^{5} \mathrm{O}$ artigo é um produto do programa "A ITCEES na dinâmica do desenvolvimento da região Norte e Noroeste do Estado do Rio Grande do Sul: o papel da implantação, desenvolvimento e consolidação de uma ITCP em uma Universidade Federal e suas contribuições para o desenvolvimento local", aprovado na Chamada Universal - MCTI/CNPq N¹4/2014.
} 